\title{
A FERROVIA E A CONSTRUÇÃO DO ESPAÇO SOCIAL DE CAMPO GRANDE-MS
}

\author{
Flavia Cristina Albuquerque Palhares Machado \\ Maria Augusta de Castilho ${ }^{2}$ \\ Sérgio Seiko Yonamine ${ }^{3}$
}

DOI: 10.5752/P.2316-1752.2020v27n40p17

\section{Resumo}

Neste artigo, serão analisadas as práticas espaciais que envolveram o complexo ferroviário da Estrada de Ferro Noroeste do Brasil e suas relações com o sítio urbano de Campo Grande/ MS, desde a celebração da sua chegada até a negação da sua presença com a retirada dos trilhos urbanos e posterior atribuição de novos usos. A partir de uma revisão bibliográfica

\footnotetext{
1. Arquiteta e Urbanista, doutoranda do programa de Pós Graduação em Desenvolvimento Local (PPGDL) da Universidade Católica Dom Bosco (UCDB). Pesquisadora dos grupos de pesquisa "Patrimônio Cultural, Direitos e Diversidade" e "Desenvolvimento Territorial Sustentável" do PPGDL da UCDB. E-mail: flaviapalharesmachado@gmail.com

2. Doutora em Ciências Sociais - História do Brasil pela Universidade de São Paulo. Docente do Programa de Pós-Graduação em Desenvolvimento Local da Universidade Católica Dom Bosco (UCDB), coordenadora do Laboratório de História, e do grupo de pesquisa na área do Sagrado no Contexto de Territorialidade e na área do Patrimônio Cultural. E-mail: m.a.castilho@terra.com.br 3. Arquiteto e Urbanista, doutorando do programa de pós graduação em Desenvolvimento Local da Universidade Católica Dom Bosco (UCDB). Atualmente é Coordenador de Relações Intergovernamentais e Institucionais no Gabinete do Prefeito da Prefeitura de Ponta Porã. E-mail: ss.yonamine@gmail.com
} 
com atenção à obra de Henri Lefebvre, será proposta uma reflexão sobre o sentido do espaço social como expressão material síntese das práticas sociais de um determinado grupo ao longo do tempo. Por fim, será atestado que a convivência dos habitantes de Campo Grande com o trem e os aspectos dessa relação são constituintes da tessitura socioespacial da cidade e mesmo a ausência do trem na vida urbana não diminui a sua importância, registrada no espaço social da cidade.

Palavras-chave: Espaço social. Ferrovia. Trem. Espaço urbano. Campo Grande. 


\section{THE RAILWAY AND THE CONSTRUCTION OF THE SOCIAL SPACE OF CAMPO GRANDE-MS}

\begin{abstract}
In this paper, the spatial practices that refrains the railroad complex of Estrada de Ferro Noroeste do Brasil and its relation with the urban site of Campo Grande/MS will be analyzed. Based on a bibliographic review with attention to the work of Henri Lefebvre, a reflection on the meaning of social space is proposed as a material expression that summarizes the social practices of a certain group over time; concluding that the coexistence of the inhabitants of Campo Grande with the train and aspects of this relations are part of the city's socio-spatial fabric.
\end{abstract}

Keywords: Social space. Railroad. Train. Urban space. Campo Grande.

\section{EL FERROCARRIL Y LA CONSTRUCCIÓN DEL ESPACIO SOCIAL DE CAMPO GRANDE-MS}

\section{Resumen}

En este artículo, se analizarán las prácticas espaciales que refrenan el complejo ferroviario del Estrada de Ferro Noroeste do Brasil y su relación con el sitio urbano de Campo Grande/MS. Basado en una revisión bibliográfica con atención al trabajo de Henri Lefebvre, se propone una reflexión sobre el significado del espacio social como una expresión material que resume las prácticas sociales de un determinado grupo a lo largo del tiempo; concluyendo que la convivencia de los habitantes de Campo Grande con el tren y los aspectos de estas relaciones dan forma al tejido socioespacial de la ciudad.

Palabras-claves: Espacio social. Ferrocarril. Tren. Espacio urbano. Campo Grande. 


\section{Introdução}

É uma imagem poderosa: o trem, "arrastando sua enorme serpente emplumada de fumaça, à velocidade do vento, através de países e continentes" (HOBSBAWN, 1986, p. 61), entra em uma cidade, mais uma vez. Um espetáculo que seus moradores acabam por se acostumar a ver, e sempre admirar. Por muito tempo, a modernidade e o progresso chegavam pelos trilhos. Mas os traçados urbanos dos trilhos ou a sinfonia da composição em movimento são apenas uma parte do complexo ferroviário que tomam as cidades, formando-as ou transformando-as. As transformações provocadas pela chegada da ferrovia nem sempre se dão de forma controlada ou pacífica e muitas vezes também envolvem conflitos na vida dos habitantes citadinos e nos sítios urbanos nos quais se inserem: o espaço urbano é o lugar da diversidade, da concentração, do adensamento, do movimento cotidiano. O espaço ferroviário impõe a especialização, a dispersão operacional, o funcionamento e a organização (MARQUES, 2014).

Neste artigo, serão analisadas as transformações das práticas espaciais no sítio urbano de Campo Grande, Mato Grosso do Sul, a começar da chegada da ferrovia na antiga Vila de Santo Antônio e do convívio do complexo ferroviário da Estrada de Ferro Noroeste do Brasil com a vida e o espaço urbano de Campo Grande. A reflexão se estende pelo contexto da chegada do trem na cidade, 
em 1914, até a retirada dos trilhos urbanos, em 2004, e a reocupação dos espaços ferroviários remanescentes. As perspectivas econômicas criadas e os conflitos sociais gerados, bem como os impactos no desenho da cidade e seus papéis na identificação na urbe modificada, reforçam a ideia de que o espaço se constrói mediante as relações e interações entre diversos atores que vivem e ocupam um determinado local de acordo com um modo de produção e de suas demandas. O estudo trata, portanto, do espaço social que envolve o complexo ferroviário de Campo Grande: da sua celebração à negação e posterior ressurgimento.

\section{0 espaço além da arquitetura e do urbanis- mo}

Muitas páginas já foram escritas com o intuito de se distinguir o que é arquitetura do que é a não-arquitetura. Seu sentido, entretanto, é indissociável da ideia de edificar, de construir espaços por meio do trabalho humano e da intenção prévia de criá-los. A visão da arquitetura como fenômeno plástico, uma escultura escavada em cujo interior o homem pode penetrar, como resume Zevi (1994), é compartilhada por muitos autores. Para o autor, o espaço pode ser compreendido a partir da demarcação de limites e da composição de vazios, ou seja, espaços interiores limitados por invólucros murais, sejam esses as paredes ou fachadas de edifícios e muros, pelos quais os homens 
possam se movimentar e viver.

O objeto da Arquitetura é, então, o espaço, cuja noção é essencialmente projetual, fruto de uma ação humana propositiva, ou seja, é "criado, originado - e não apenas modificado ou transformado - pela e para a ação humana, ante um ambiente natural que se dá como espaço para o homem, preexistente, portanto, a qualquer ação humana" (LEITÃO e LACERDA, 2016, p. 810). O espaço arquitetônico, por consequência, distingue-se do espaço pré-existente ou natural e é entendido através de sua materialidade, um espaço "projetado", objeto do fazer arquitetônico.

No entanto, o espaço nem sempre foi expresso como objeto pela própria arquitetura e, durante séculos, não foi sequer mencionado. Vitrúvio, arquiteto romano que viveu no século I a. C., em seu tratado "Da Arquitetura", afirma que a arquitetura consiste em "ordenamento, disposição, eurritmia, proporção, conveniência e agenciamento." (POLIÃO, 1999, p. 54). Seus princípios conceituais para a arquitetura "utilitas" (utilidade), "venustas" (estética), e "firmitas" (solidez) nortearam os arquitetos até os dias atuais e constituem aspectos qualitativos de edificações cujo espaço não era enunciado. Ao longo da história, a arquitetura se orientou com base em pressupostos estéticos, formais ou funcionais, enquanto o espaço permanecia como uma noção implícita que prescindia de qualquer 
conceituação. As construções arquitetônicas foram apreciadas por séculos à luz dos mesmos critérios aplicados a pintura ou escultura, ou seja, critérios estético-formais. Somente a partir do século XX o espaço passou a fazer parte do discurso da arquitetura, embora os arquitetos ainda dirijam com mais frequência suas atenções à estética do espaço ou as suas funções, ou seja, aos atributos da sua materialidade, do que à essência do espaço propriamente dita.

Sendo o espaço arquitetônico, conforme mencionado anteriormente, produzido diante uma ação propositiva e compositiva humana, pode ser, então, examinado como "uma forma genérica de expressão que efetivamente informa o homem (com a qual os homens se informam, de modo consciente ou não) e como detentor de sentidos passíveis de uma formalização necessária para a operação sobre esse mesmo espaço, para a prática arquitetural." (TEIXEIRA COELHO, 1999, p. 15). Dessa maneira, o espaço pode ser entendido como a base de uma linguagem através da qual os arquitetos se expressam ao projetar. Seus aspectos o tornam interpretável e o homem ganha importância não só como idealizador do espaço, mas também como utilizador, como seu "vivenciador." Suas características determinam o uso e a experiência humana, mas também são igualmente determinadas por estes na medida em que podem ser interpretadas e, por isso, influenciadas (HERTZEMBERGUER, 1996, p.93). 
Sob o olhar da sua possibilidade de explicitar sentidos e significados, o espaço transcende a arquitetura, que intenta construí-lo materialmente, e transforma-se também em objeto de outros campos de estudo, embora seja tratado de maneira fragmentada, de acordo com a ciência que o examina, conforme lembra Lefebvre (1991). A filosofia, de acordo com o autor, seguia a tradição aristotélica em que espaço era compreendido como uma categoria, assim como o tempo, a qual permitiria classificar as evidências apreendidas pelos sentidos, embora seu estatuto permanecesse incerto. A lógica cartesiana, a datar do século XIV, trouxe o espaço para o domínio absoluto: "as Object opposed to Subject... space came to dominate, by containning them, all senses and all bodies"4 (LEFEBVRE, 1991, p.1). Esse autor nota que Kant recuperou a noção de categoria, compreendendo o espaço como pertencente a um domínio a priori da consciência do sujeito, parte de uma estrutura inapreensível, sem deixar de abordá-lo como uma ferramenta de conhecimento, um meio de classificação de um fenômeno. Essas controvérsias foram ampliadas com a apropriação do termo espaço (bem como do tempo, como nota Lefebvre) pelos matemáticos, que de forma paradoxal o tornaram parte do seu domínio e criaram, a partir da linguagem matemática, no-

4. "Como objeto diante do sujeito [...] o espaço vem a dominar porque os contém, os sentidos e os corpos." (p.1). Tradução dos autores. 
vos espaços (não-euclidianos, curvos, etc.), acentuando a dificuldade em se estabelecer um estatuto para a sua compreensão.

A epistemologia, mais recentemente, seguindo a tradição filosófica sobre o espaço acrescida da visão adquirida através da matemática, adotou um estatuto do espaço como "coisa mental" ou "espaço mental" 5 . Essa noção de espaço mental se generalizou sem que the fossem impostos limites, proliferando-se múltiplos espaços (espaço literário, cultural, ideológico, etc.). Posteriormente, a linguística juntou-se à epistemologia e a filosofia, cultivando, conforme critica Lefebvre, uma noção de espaço fetichista em que o "espaço mental" envolveria o espaço social e físico, sem uma possibilidade de mediação entre estes $^{6}$. Os estudos nessas disciplinas não foram capazes de propiciar, conforme aponta o autor, "um eixo para uma 'ciência do espaço', constituindo muitas vezes inventários sobre que há no espaço, descrições do espaço, e até discursos sobre o espaço, mas não permitem constituir um 'conhecimento' (knowledge) do espaço". (LEFEBVRE,

5. "mental thing" e "mental place", conforme tradução para a língua inglesa. (LEFEBVRE, 1991, p.3.)

6. De acordo com as palavras de Lefebvre, na tradução para o inglês:

"My cristicism certainly applies in full force, however, to Julia Kristevas's ..., to Jacques Derrida's 'grammatology' and to Roland Barthe's general semiology. This school, whose growing renown may have something to do with its growing dogmatism, is forever promoting the basic sophistry whereby the philosophic-epistemological notion of space is fetishized and the mental realm comes to envelope the social and physical ones" (LEFEBVRE, 1991, p.5). 
1991, p. 3).

Embora não haja consenso entre as ciências sobre o espaço como objeto de estudo, é tácito que os espaços carregam consigo uma enorme gama de significados e sentidos. Teixeira Coelho (1999, p. 127) afirma que os espaços podem ser semantizados, suprassemantizados ou até dessemantizados, mas que não são jamais neutros, vazios ou carentes de significados. Segundo o autor, os processos de significação dos espaços são complexos e abertos, abrangendo as relações sociais que neles se dão, além das representações dos sujeitos elaboradas individualmente, por entre as relações com os demais e com o meio ao qual está inserido. Essa construção semântica se inicia por efeito dos estímulos e referências percebidas e vividas pelo corpo.

De maneira semelhante, Lefebvre (1991) aponta a complexidade de significados e sentidos do espaço, apresentando-o, assim como as relações sociais, como produtos e realizações de um determinado modo de produção em determinado tempo. O espaço seria o fruto destas relações de produção, bem como das relações e interações sociais, culturais, temporais e simbólicas, da linguagem e das práticas políticas e do uso do poder, as quais se projetam em um terreno que se transforma a partir delas e acaba por transformá-las, apresentando, assim, a ideia de 
espaço social (LEFEBVRE, 1991)7. Conforme o autor, cada modo de produção se apropria de um espaço preexiste e consolidado, organizando-o para seus fins em novos arranjos espaciais, constituindo instrumento ao pensamento e à ação, sendo ao mesmo tempo produto e meio de produção. O espaço explicitado por Lefebvre (1991, p. 18) "é uma 'abstração concreta'8, real como a mercadoria e o dinheiro, mas abstrato pelas relações que nele estão contidas, ou seja, as relações sociais, sendo instrumental tal e qual o conhecimento".

A natureza, ou seja, o espaço original, transforma-se em matéria-prima ou suporte sobre o qual as forças produtivas de diferentes organizações ou grupos sociais forjam seus próprios espaços. O espaço natural, aponta Lefebvre, está desaparecendo inclusive do pensamento humano, uma vez que é impossível recriá-lo como era antes da ação humana. Em consequência, cada sociedade e cada modo de produção, com suas especificidades, produzem um espaço próprio que vem a ser o espaço social, o qual é formado, portanto, por lugares apropriados às práticas e relações sociais de reprodução determinadas pelas relações entre os sexos, entre grupos demográficos e

7. ....spatial practice consists in a projection onto a field of all aspects, elements and moments of social practice. In the process these are separated from one another, though this does not mean that overall control is relinquishes even for a moment: society as a whole continues in subjection to political practice - that is, to state power". (LEFEBVRE, 1991, p. 08).

8. "concrete abstraction" 
pelas diversas organizações familiares e às relações de produção (a divisão do trabalho, dos meios de produção e de sua organização e a hierarquia das funções sociais e de potência). Como consequência, compreende-se que o espaço social enunciado por Lefebvre distingue e "localiza" essas funções sociais que são imbricadas e não se separam, uma vez que a divisão do trabalho repercute na organização familiar e nela se sustenta. Essa, de igual maneira, interfere na divisão do trabalho. Nesse sentido, "in reality social spaces 'incorporates' social actions, the actions of subjects both individual and collective who are born and who die, who suffer and who act" (LEFEBVRE, 1991 , p. 33) ${ }^{9}$.

As relações de produção e as ordens por essas impostas forjam, conforme Lefebvre, as representações do espaço, as quais abrangem o conhecimento, as ciências, os signos e códigos de uma sociedade. Essas representações são elaboradas intelectualmente a partir das informações e percepções do espaço vivido e determinam as concepções sobre o espaço. O espaço concebido constitui, portanto, o objeto dos planificadores, arquitetos, geógrafos, urbanistas, dos tecnocratas e gestores e que pode ser expresso através de sistemas de códigos e da linguagem, destacando seu caráter objetivo. O saber,

9. "Na verdade, o espaço social "incorpora" ações sociais, ações de sujeitos ao mesmo tempo coletivos e individuais, que nascem e morrem, padecem e agem." (LEFEBVRE, 1991, p. 33), tradução dos autores. 
no entanto, pode ser o disfarce de ideologias, permitindo que conhecimento e ideologia se misturem nas práticas das representações do espaço. Esse espaço concebido é, logo, "o espaço semantizado e que pode ser condicionado ideologicamente revelando um discurso espacial" (TEIXEIRA COELHO, 1999, p.117-127).

Por sua vez, os espaços de representação distinguidos por Lefebvre são apropriados pela imaginação, envoltos por imagens e complexos simbolismos, sejam esses codificados ou não. Esses são os espaços habitados e vividos pelos sujeitos e pela coletividade, essencialmente qualitativos, compreendendo em si também os aspectos transcendentes da vida cotidiana. Ligados às emoções, aos afetos, à percepção, aos sentidos e às memórias dos sujeitos que ali vivem ou viveram, os espaços de representação são envoltos em um caráter temporal e histórico. O espaço vivido está sempre no presente, não obstante as marcas, memórias ou evidências do passado.

Os espaços ou lugares produzidos por uma determinada sociedade para produção e para reprodução social, ou seja, os espaços de representação e as representações do espaço, bem como as relações entre os sujeitos que vivem nestes espaços, individuais ou coletivos, constituem o que o Lefebvre denomina 'prática espacial'. Lefebvre (1991) nota ainda que a prática espacial, assim como as demais práticas sociais, é percebida e vivida an- 
tes de ser concebida ou conceituada e, contrário ao que se supõe, o espaço concebido tomado em primazia sobre aquele que é 'vivido' acaba por limitar ou extirpar a própria vida do espaço. ${ }^{10}$

As transformações dos modos de produções ocorrem de maneira gradativa e o mesmo ocorre, portanto, com o espaço social: os lugares e os espaços se adequam às novas demandas dos novos modos de produção, em um constante processo de transformação dos espaços sociais. As relações entre os espaços vividos, concebidos e percebidos não são lineares, simples ou estáveis: a prática espacial, as representações do espaço e os espaços de representação intervém de múltiplas maneiras na produção dos espaços, de acordo com suas distintas propriedades, qualidades, épocas e sociedades.

Entretanto, a correspondência entre um modo de produção e o espaço por ele forjado não implica na simultaneidade temporal, visto que todos os elementos que concorrem para as relações entre todos os atores sociais e o meio em que interagem e vivem acabam por formar um amplo e complexo sistema com camadas de informações e significados. As transformações se dão através de

10. "Like all social practice, spatial practice is lived directly before it is conceptualized; but the speculative primacy of the conceived over the lived causes practice to disappear along with life, and so does very little justice to the 'unconscious' level of lived experience per se." (LEFEBVRE, 1991, p. 34). 
processos de transições cuja temporalidade é decorrente das relações dialéticas entre todos os agentes e da potência de cada um ao longo do processo. Dessa forma, a história do espaço e da sua produção e reprodução material, formal e representativa não é linear nem se confunde com o encadeamento ou sucessão dos fatos e acontecimentos históricos ou de costumes, "leis, ideias ou estruturas socioeconômicas ou políticas, nem tampouco pode ser periodizada tal e qual a história dos demais aspectos de uma sociedade." (LEFEBVRE, 1991, p. 46).

A história dos espaços narrada por Lefebvre tem como marco o espaço absoluto, espaço natural povoado socialmente por forças políticas e religiosas. Esse é composto por fragmentos da natureza que têm seus atributos incorporados simbolicamente às práticas sociais para as quais é consagrado. Esses espaços dão lugar a ritos e cerimônias consagrados à reprodução das forças sociais que, para isso, evocam as forças da natureza, ou seja, são espaços de representação, altamente semantizados. Podem ser uma caverna, uma clareira em meio à selva, uma nascente, uma fonte, um rio, uma floresta: um espaço natural do qual é subtraído o seu sentido natural e sobre o qual são atribuídos sentidos sociais. Decorrente do espaço absoluto, origina-se o espaço histórico, o espaço apropriado pelas sociedades pré-capitalistas. Esse espaço assenta-se sobre o espaço absoluto que permanece como uma camada ou sedimento, relativizando as rela- 
ções políticas e religiosas e materializando as suas representações por intermédio do trabalho humano: o espaço constituído a partir do modo de produção feudal e de suas variantes ou particularidades locais, por exemplo, espaço de castelos, catedrais, monastérios fixados em meio à paisagem transformada pelas comunidades camponesas e pela rede de comunicação, de caminhos e estradas que começava a se construir (LEFEBVRE, 1991, p. 31).

As transformações para o modo de produção capitalista promoveram novos sentidos para a atividade produtiva e o trabalho, desligando-os das representações do mundo e da vida social, política e religiosa e da sua reprodução social, erigindo um novo espaço o qual passa a constituir ele próprio um objeto significável e mensurável, passível de quantificação, cujo valor passa a ser de troca e não mais de uso. Esse espaço assenta-se sobre os demais (absoluto e histórico), os quais permanecem como vestígios ou suporte para este novo espaço, ao qual Lefebvre (1991) atribui um caráter abstrato e por isso the denomina espaço abstrato. Tal abstração faz com que as representações do espaço esvaziem os espaços de representação simbólica e os espaços vividos. O espaço abstrato distancia e subjuga a natureza, transforma-a em recurso, atribui-Ihe valor e a ela refere-se nostalgicamente. O mesmo faz com o espaço histórico: transforma-o em registro nostálgico cujos conteúdos, sentidos ou significados originais vão sendo arrancados. 
Concebido objetivamente, o espaço abstrato é apropriado com base no conhecimento em detrimento da percepção dos sentidos e da vivência. Como consequência, esse espaço é produzido de maneira homogeneizada, negando as diferenças oriundas das condições naturais, históricas, culturais, materiais e, assim, sociais. Entretanto, embora homogêneo, o espaço tornado objeto também passa a ser fragmentado, numa condição bastante contraditória: desvanecem-se os limites e fronteiras e, ao mesmo tempo que se fragmentam, recortam-se ou especializam-se os espaços. Desse modo, como os trabalhos na divisão social e técnica do trabalho, os espaços também se tornam especializados, separados em partes cuja localização e função são distintas. O espaço abstrato consolidado pelo modo de produção capitalista é produzido analogamente à produção industrial: o espaço-objeto-produto é homogeneizado para que possa ser vendido, trocado ou comprado, reduzindo-se as diferenças apenas àquelas que podem ser quantificadas monetariamente. Esses espaços são repetitivos como são os gestos dos trabalhadores e especializados tal e qual as etapas de produção industrial. A divisão social do trabalho se concretiza no espaço em diversas escalas: nas habitações (nas máquinas de morar, enunciada por Le Corbusier no princípio do século $X X$ ), nas cidades (exemplificando-se através dos zoneamentos urbanos) ou, ainda, globalmente (através da especialização produtiva de países e regiões). 


\section{Campo Grande e o trem}

As terras que hoje dão lugar ao Estado de Mato Grosso do Sul pertenciam ao grande território dos índios guarani que já tinham sido partilhadas entre os governos espanhol e português, a começar da chegada dos expedicionários europeus por volta dos anos de 1539 a 1556 (GRESSLER, 1988). A Guerra do Paraguai, travada no período do $2^{\circ} \mathrm{Im}-$ pério, entre 1864 e 1865, contribuiu para esvaziar vasta porção territorial ${ }^{11}$ que viria a constituir, posteriormente, uma faixa de fronteira Brasil/Paraguai (DORATIOTO, 2002). Com o fim do conflito, os dois (Brasil e Paraguai) passaram a reocupar esses territórios impactados. As pequenas vilas que surgiram na região e a vinda de imigrantes em busca de novas oportunidades fazem parte dessas estratégias de ocupação dos territórios fronteiriços.

Além das providências militares para garantir a segurança nacional implantadas, outra estratégia geopolítica adotada foi viabilizar modos logísticos para a efetiva ocupação do oeste brasileiro, isolado, precário e ignorado (QUElROZ, 2004). Nesse sentido, duas estradas de ferro foram projetadas: Estrada de Ferro Madeira - Mamoré, nos anos 1900, em Rondônia, e a Estrada de Ferro Noroeste do Brasil, inaugurada em 1914. Essa última foi pensada para

\footnotetext{
11. Segundo Doratioto, a invasão paraguaia à antiga Província de Matto Grosso, se estendeu, pelo Rio Paraguai até o Rio São Lourenço e por terra até onde hoje são os municípios de Miranda e Coxim.
} 
suportar as fronteiras com o Paraguai e com a Bolívia: seu desenho partia da cidade de Bauru e levava a linha férrea até as cidades de Ponta Porã e Corumbá, interligando-as com São Paulo e ao Porto de Santos.

Boa parte da história recente do desenvolvimento das cidades e também do surgimento de novos sítios urbanos se desenrolou juntamente às estradas de ferro, ou ao longo dos seus traçados e trajetos. O trem se inscreveu no espaço social das cidades e alimentou o imaginário popular:

Nenhuma outra inovação da revolução industrial (pode-se dizer até hoje) incendiou tanto imaginação quanto a ferrovia, como testemunha o fato de ter sido o único produto da industrialização do século XIX totalmente absorvido pela imagística da poesia erudita e popular (ARRUDA, 1995, p.5).

O Álbum Gráphico de Matto Grosso, publicado em 1914, na página 410, descreve o vilarejo de Campo Grande, fundado havia três décadas, no ano da inauguração da estação ferroviária:

A villa de Campo Grande está situada no planalto da Serra Maracajú, n'uma altitude de 735 mtrs., pelos $20^{\circ} 27^{\prime} 15^{\prime \prime}$ de latitude e $11^{\circ} 36^{\prime} 53^{\prime \prime}$ de longitude o do Rio de Janeiro. Há pouco mais de dois anno, era um vilarejo insignificante, contando apenas cento e tantas casas, em sua maioria de páo a pique, e uns 1200 habitantes: actualmente possua cerca de 500 fogos e contando com uma população fixa de nunca menos de 5000 almas. 
Campo Grande era então apenas um aglomerado de apoio a atividade rural que começava a se desenvolver na região dos Campos da Vacaria e que passava a contar repentinamente com uma ligação privilegiada com os centros urbanos mais desenvolvidos do país. Nesse período as cidades-polo do estado eram a capital Cuiabá e Corumbá, na beira da hidrovia do Rio Paraguai, possuindo um dos mais importantes e movimentados portos fluviais do Brasil. O sul do Mato Grosso ainda estava por se realizar. Deve-se registrar ainda que em 1920 se instala na cidade o complexo do Comando Militar do Oeste, que constituiu outro evento de inflexão no desenvolvimento de Campo Grande.

\subsection{O espaço simbólico}

A modernidade e as máquinas estão indelevelmente interligadas, para o bem e para o mal. A esperança em um mundo melhor que a tecnologia poderia trazer está impregnado no imaginário de gerações de populações e projetos de vida foram construídos baseados nessa crença. O trem é um dos ícones que, no século passado, representavam esse anseio coletivo.

Por todo o mundo, a construção dos trilhos de ferro, passou a marcar, na imaginação das pessoas, a chegada do progresso ou da modernização. O apito do trem trazia a reconfortante sensação, para as pessoas - por mais distantes que estivessem, de estarem ligadas ao mundo, de serem civilizadas, de serem contemporâneas. (ARRUDA, 1995, p. 6). 
As poderosas imagens suscitadas pela passagem do trem se popularizaram e se reproduziram inclusive por meio da música. O "Trenzinho do Caipira", por exemplo, é uma composição de Heitor Villa Lobos mundialmente conhecida e parte integrante da peça Bachianas Brasileiras $n^{\circ} 2$, composta em 1930. A obra se caracteriza por imitar o movimento de uma locomotiva com os instrumentos da orquestra e, em 1975, Ferreira Gullar acrescentou-lhe a poesia que descreveu em palavras as emoções provocadas pelo trem e pela música. Adoniram Barbosa, em 1964, compôs "Trem das Onze" que descreve o trem como parte da vida urbana da cidade de São Paulo. Além disso, o Mato Grosso do Sul tem sua canção símbolo "Trem do Pantanal", composta na década de 1970, por Geraldo Roca, que evoca o percurso do trem que passa por Campo Grande rumo a Corumbá, para então alcançar a Bolívia.

O espaço urbano histórico é, assim, concebido e apropriado de significados dadas as crenças e eventos coletivos acontecidos, ressaltando que não são lineares, nem correspondem temporalmente aos períodos históricos marcados por mudanças socioeconômicas, políticas e culturais de uma sociedade, (LEFEBVRE, 1991). Em Campo Grande, mesmo antes da chegada do trem, a ferrovia já era utilizada como referência espacial e temporal. A linha do trem em construção provoca, ainda que sem sua conclusão, mudanças no parcelamento do solo e, em 
consequência, nos aspectos da ocupação urbana de Campo Grande. Em 1913, conforme registra ARRUDA (1995, p.36), a Câmara dos Vereadores autorizava a doação de terrenos de acordo com o traçado da ferrovia:

Art. $2^{\circ} \mathrm{A}$ reservar os terrenos, da margem direita do córrego Segredo entre [...] e o traçado da Noroeste do Brasil... (...) art. $3^{\circ} \mathrm{A}$ permutar os terrenos situados entre a face oeste do prolongamento da rua Santo Antonio, o traçado da Noroeste do Brasil [...]

No cotidiano impactado, a linha férrea e a estação ferroviária passam a ser referência dos acontecimentos cotidianos. A estação ferroviária e os horários estabelecidos pela chegada e partida dos trens tornaram-se rapidamente referência de espaço urbano e de tempo para os habitantes da cidade. Sua localização no território urbano é utilizada para registro de inquéritos policiais, imóveis passam a ser identificados em relação aos trilhos e estabelecimentos comerciais fazem referência à ferrovia em gestação. Uma nova etapa na vida urbana é assumida. Os trilhos e a estação são os símbolos dessa nova e auspiciosa era.

\subsection{0 espaço concebido e o espaço social}

A ferrovia não foi querida pelos campo-grandenses e nem era considerada como uma conquista da sociedade local. Na verdade, fruto de interesses externos, passava apenas por Campo Grande em direção às fronteiras boli- 
viana e paraguaia, as cidades de Ponta Porã e Corumbá. Constituía, na realidade, um projeto nacional do qual os participantes locais eram passíveis espectadores da sua chegada (QUEIROZ, 2004).

O complexo arquitetônico-urbanístico ferroviário campo-grandense (Figura 1), cuja parte mais conhecida e visível para os moradores são os trilhos urbanos e a estação ferroviária, é bastante extensa e explica, em parte, os impactos urbanísticos que causou na cidade. Fazem parte do complexo: o trecho urbano da linha férrea, a estação ferroviária e a esplanada (cerca de 23 hectares, equivalentes a 23 quarteirões urbanos) que continha mais de 150 edificações, dentre oficinas, armazéns, galpões, escritórios e a rotunda, sendo esse conjunto complementado pela vila ferroviária, as casas dos funcionários de nível intermediário e as dos funcionários graduados. Inclui, finalmente, um clube social e uma escola. O complexo está situado na porção central da cidade. Deve-se registrar ainda a construção nos arredores da cidade de mais duas estações, Água Rica e Manoel Brandão, que também, e de certa forma, integravam a vida dos moradores de Campo Grande.

A arquitetura ferroviária (se existisse essa classificação arquitetônica) é peculiar, com linguagem padronizada em toda a extensão da rede em todas cidades que a recebe, sendo facilmente reconhecida independente da configu- 
ração urbana ou das expressões arquitetônicas que essas possam ter. É como um brand, mais memorizado que o próprio logotipo da empresa. A rotunda sempre tem um grande impacto na paisagem urbana e a estação de trem é fortemente vinculada ao patrimônio mnemônico e cultural do local. O espaço arquitetônico forjado pela ferrovia, tal qual afirma Teixeira Coelho (1999) em consonância com Lefebvre (1991), constitui-se como uma forma de expressão capaz de informar sobre o seu funcionamento e de formalizar sentidos e significados para a prática espacial dos seus habitantes. 


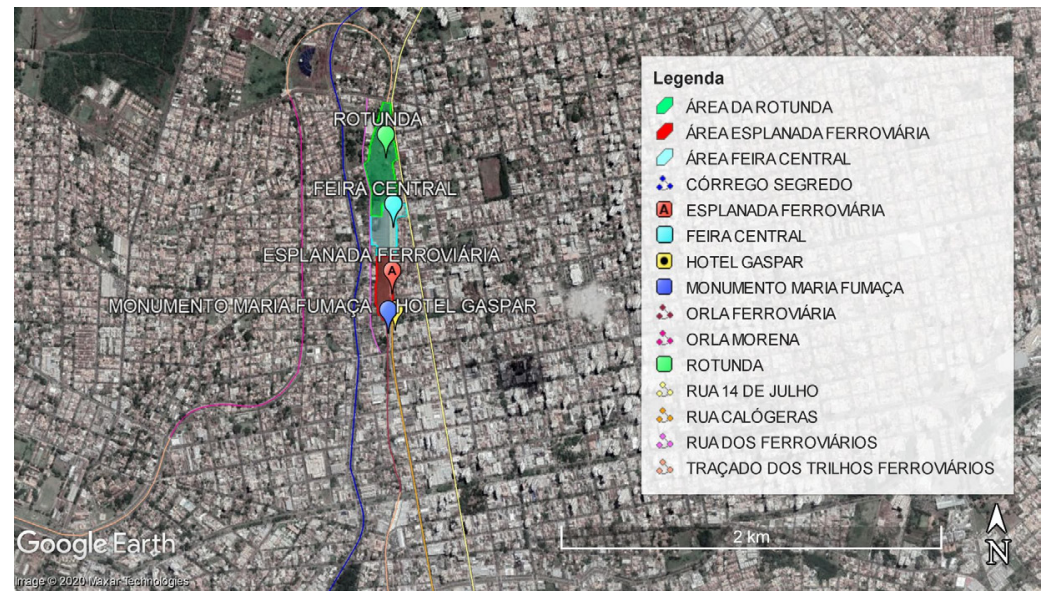

Figura 1 | Mapa da Área Central de Campo Grande - Localização do Complexo Ferroviário, do Traçado da Ferrovia da Noroeste do Brasil.

Fonte: Elaborada pelos autores (Imagem base: GoogleEarth Pro, 2020). 
Ainda sobre o espaço ferroviário arquitetônico e sua linguagem é importante notar que esse não se reproduz na cidade. O estilo, ou o próprio sistema construtivo, não se manifestam em outros lugares ou edificações campo-grandenses, parecem ser considerados como algo exclusivo da ferrovia. O Hotel Gaspar foi construído contíguo à estação ferroviária em 1954 e empreendido quase exclusivamente em função da estação ferroviária. Entretanto sua arquitetura desconsiderava o poderoso referencial e assumia decididamente uma linguagem modernista, como se afirmasse: 'ali do lado é o espaço arquitetônico da ferrovia, aqui é o espaço arquitetônico de Campo Grande'. O Hotel foi o mais importante da cidade por muitos anos (REZENDE, 2018, p. 54), encerrando suas atividades em 2020. A edificação não é tombada pelo patrimônio municipal, mas está inserida na Zeic (Zona Especial de Interesse Cultural) e foi inventariado pelo Plano Diretor de Campo Grande (Figura 2). 

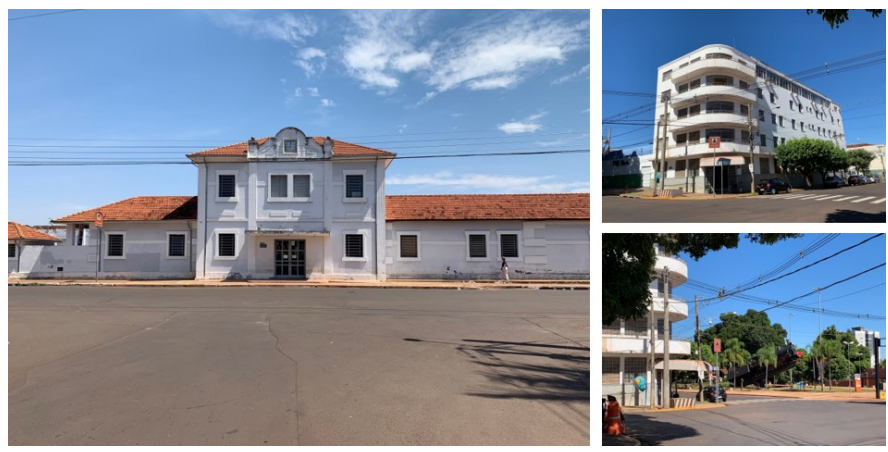

Figura 2 | Imagens da Estação Ferroviária (a esquerda), do Hotel Gaspar (acima, a direi-

ta) e do Monumento Maria Fumaça (abaixo, a direita), no início da Orla Ferroviária.

Fonte: Fotos dos autores, 2019.

A construção social do território/espaço social campo-grandense foi bastante marcada pela vinda de engenheiros e técnicos, especialmente por aqueles que chegaram para a construção da ferrovia e, posteriormente, pelos que vieram para instalação da área militar do Comando Militar do Oeste. Esse grupo trouxe técnicas desconhecidas em Campo Grande alterando pela primeira vez os rumos e os sentidos do desenvolvimento da cidade, inscrevendo sua marca na representação do espaço da cidade.

É possível afirmar que a ferrovia deflagra o processo de modernização em Campo Grande, trazendo à cidade propostas de organização urbana pensadas pelos seus engenheiros, encarregados de estudar o traçado da estrada de ferro Noroeste do Brasil. Logo, em 1906, chefiadas pelo Engenheiro Emílio Schnoor, as construções começaram; no entanto, em 1909, a pequena vila passou a ter um traçado urbanístico elaborado pelo Engenheiro Agrimensor Nilo Javary Barém, a pedido da 
Intendência Municipal. A planta do Plano de Alinhamento de Ruas e Praças de Campo Grande foi traçada em direção aos pontos cardeais e ortogonais; as quadras foram dispostas em formato de xadrez. (TRUBILIANO, 2012, p. 113).

O impacto urbanístico causado foi acompanhado de um delicado processo de rearranjo social. Como toda grande obra, a implantação da ferrovia atraiu levas de trabalhadores de outras regiões do Brasil e de imigrantes de outros países, que desequilibraram a ordem originalmente estabelecida ao longo do tempo e da evolução social da cidade em curso até então. O espaço produzido a partir da passagem da ferrovia por Campo Grande é fruto dessas relações de produção, assim como das relações e interações sociais, coletivas e também subjetivas, entre os atores e o meio, projetadas sobre o terreno, transformando-o e, por ele, transformadas, conforme apontado por Lefebvre (1991). Ao entrar em funcionamento, a ferrovia questionava o ordenamento social existente, criando novas elites, novas lideranças e inéditas modalidades de segregação:

Por exemplo, os trilhos da NOB acabaram por dividir o espaço pelos habitantes é revelador de outros aspectos da ferrovia como veremos. O espaço que ficou do lado de baixo dos trilhos foi, e ainda é considerado até hoje, como local dos pobres, bairros populares, - lado de cima, local dos ricos, de atividades nobres. Não por acaso deste lado foram construídos o Banco do Brasil, a Câmara Municipal, etc. (ARRUDA, 1995, p. 33). 
Possivelmente pela necessidade de espaços maiores, o complexo ferroviário foi construído no lado norte do município, relativamente distante (para a época) do centro de Campo Grande, que se distribuía perto do córrego Prosa, no entorno da Rua 26 de Agosto. Criou-se com isso uma nova espacialidade ao longo e ao redor das ruas Calógeras e 14 de Julho que passaram a constituir uma nova centralidade urbana, concentrando a atividade comercial, que nessa época já tinham um alcance regional.

\footnotetext{
Siqueira (2012), no Jornal Correio do Estado também divulgou sobre a fala de um comerciante árabe entrevistado da Avenida Calógeras, que assim se manifestou em fevereiro de 2012: O pessoal vinha de trem, almoçava no centro e depois vinha fazer compras nas lojas. Eram famílias inteiras. Nós abríamos até domingo para atendê-las. (CUNHA, 2017, p. 75-76)
}

No trecho paulista, a atuação da NOB foi revestida de grande êxito, expandindo efetivamente a sua frente econômica. No entanto, o trecho sul mato-grossense teve desafios muito maiores, certamente derivadas das condições próprias às atividades produtivas no Mato Grosso do Sul e ao seu desenvolvimento, muito diferente dos processos de desenvolvimento em curso no restante do País, "o que fez com que a ferrovia funcionasse permanentemente em regime deficitário" (QUEIROZ, 2004, p. 486).

Paradoxalmente ao progresso que o modo ferroviário imprimiu às cidades do Mato Grosso, a NOB acabou por 
entrar em decadência financeira e administrativa. Mesmo com o seu sucesso operacional, findou em pacote de privatização, junto com outras empresas estatais brasileiras na onda de privatizações neoliberais que se instalou no Brasil nos anos 1990. A empresa foi vendida passando a ser operada pelo setor privado oferecendo apenas o transporte de carga. O corredor de imigração, que trouxe ao estado verdadeiras levas de aventureiros, trabalhadores e empreendedores em busca de nova vida, foi encerrado.

\subsection{O espaço abstrato e o não-espaço}

Em uma segunda-feira do ano de 2004, a cidade amanheceu sem os trilhos. As principais avenidas estavam solenemente asfaltadas. A maioria das pessoas que passaram por esses cruzamentos, nesse dia, sequer notou a ausência. Uma pequena polêmica se instalou e passou. A operação ferroviária urbana já tinha sido desativada há tempos. Um episódio da história urbana de Campo Grande foi repentinamente encerrado. 


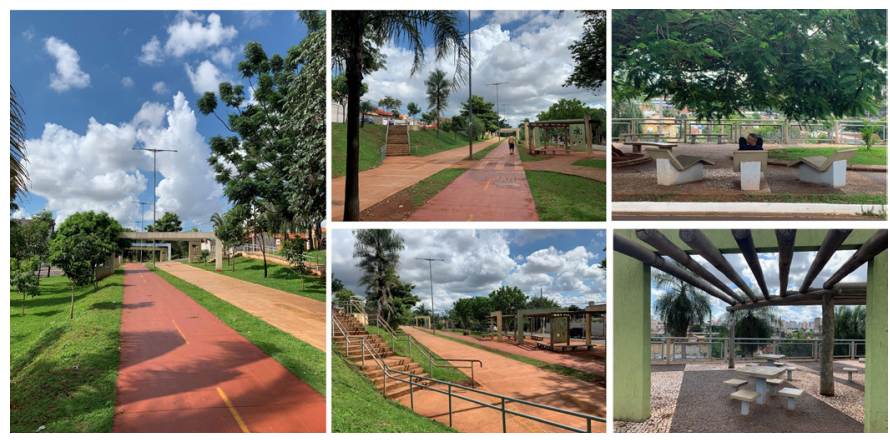

Figura 3 | Imagens do Parque Linear Orla Morena.

Fonte: Fotos dos autores, 2019.

Sobre esta questão, vale lembrar o pensamento de Lefebvre, anteriormente descrito, sobre a emergência do espaço abstrato, o qual se inscreve sobre os traços ou registros das práticas sociais e espaciais anteriores, mantendo-os como vestígios das transformações provocados no espaço pelas mudanças nas atividades produtivas típicas do modo de produção capitalista. Assim se deu em Campo Grande com o legado da ferrovia para produção do espaço atual da cidade.

Iniciativas públicas têm se dirigido à revitalização do centro de Campo Grande, incluindo o complexo ferroviário. Algumas obras já foram implantadas referentes aos espaços ferroviários desativados. Os espaços onde existiam os leitos dos trilhos urbanos se transfiguram em outro tipo de leito urbano e os corredores ao longo desse leito 
disfuncional, são atualmente denominados: Orla Morena (Figura 3) e Orla Ferroviária (figura 4), fruto de projetos de revitalização urbana desenvolvidos pela Prefeitura Municipal cujas obras foram concluídas e inauguradas em 2010 e 2012, respectivamente. Esses projetos tinham por objetivo implantar equipamentos de lazer e esporte, legando vagas referências ou vestígios (como exemplo, os pequenos fragmentos de trilhos que foram mantidos) da importância da ferrovia para a história da cidade e das práticas sociais e espaciais daqueles que ali viveram e ainda vivem.
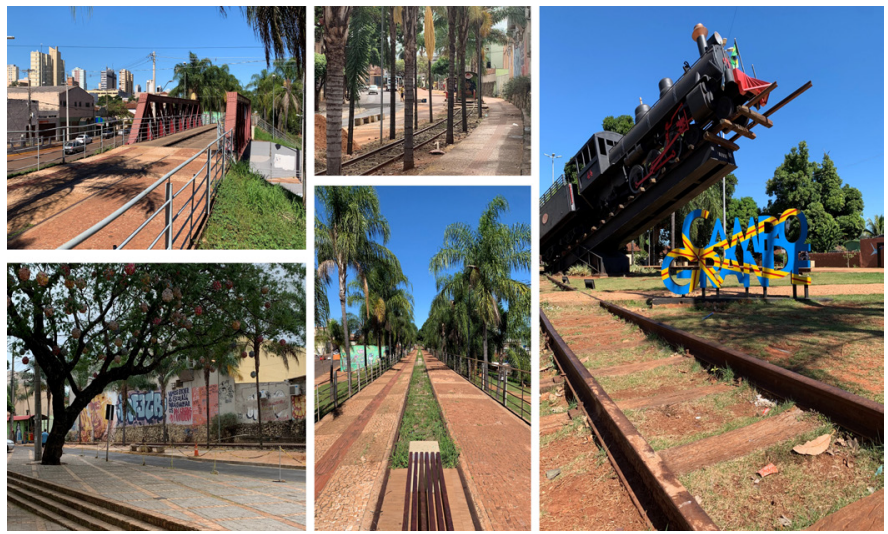

Figura 4 | Imagens do Parque Linear Orla Ferroviária.

Fonte: Fotos dos autores, 2019. 
Na esplanada ferroviária, a antiga estação foi transformada em um espaço cultural e de eventos, tendo a partir do final da primeira década do século XXI, passado a abrigar as festividades carnavalescas da capital, como por exemplo o Cordão da Valu, que marca a retomada desse tipo de manifestação cultural em Campo Grande. Parte do pátio ferroviário foi transmutado em um simulacro da antiga Feira Central (a tradicional 'Feirona', que acontecia em outro local e que marcava um dos principais pontos de encontro da cidade e legítima atração turística), inaugurada em 2004, onde desde então acontecem anualmente o Festival do Sobá e a Festa do Peixe, além de comemorações populares de outras datas festivas.

Neste caso o patrimônio ferroviário de Campo Grande não recebeu um apelo voltado ao seu significado enquanto símbolo da memória coletiva; foi usado para agregar valor econômico as intervenções urbanas municipais, sendo utilizado como âncora para criação de um novo urbano, constituído pela requalificação da região onde antes era conhecido apenas pela presença da ferrovia. [...] Com isso, entende-se que a revitalização do complexo dissolve a memória ferroviária como conjunto, fragmentando uma percepção de processo histórico, não traz um apelo a memória ferroviária na cidade, e sim uma valorização do entorno do elemento que nada remete a ferrovia, a feira central. (MARQUES, 2014, p. 86-87).

O não-espaço, como utilizado, é emprestado da conceituação postulada por Ribeiro (2008, p. 8-9) referindo-se às viagens para campos de concentração: "Nesta viagem, a sucessão de lugares é apenas aparente, já que acontece, 
não no tempo, mas num espaço estagnado, rigidamente estruturado, de que estão ausentes todos os pontos de referência familiares e que é assim, percebido pelo sujeito como um não-espaço". Essa imagem pode ser combinada a ideia de viagem não-sentimental, escrita por Albert Drach, citado por Ribeiro (2008) em seu artigo no qual relata uma viagem em que o viajante, deitado num banco num estado de semi-consciência, não consegue se lembrar de ter comprado o bilhete e não faz ideia de para onde está sendo levado. O comboio avança sem parar, o sentido do tempo se perdeu, como é indicado pela perda da memória do narrador e cuja situação é definida pelos traços dominantes do confinamento e da paralisia.

É realmente uma referência desconfortável, mas pertinente aos argumentos desta reflexão: o não-espaço se refere a uma situação-contexto no qual o observador/sobrevivente perdeu todos os referenciais familiares e que perde totalmente a noção do tempo, enquanto trajetória da vivência que está tendo. A impossibilidade de processar territorialidades e espacialidades por absoluta perda de referenciais, espaço-temporal pode levar a uma paralisia inconsciente, em que os atores do espaço/território podem ser levados a estados de alienação, segregação e paralisia social. É uma descrição dramática, que já está acontecendo em nano-escala em Campo Grande e outras cidades, e em preocupante crescimento. 


\section{Considerações finais}

Um ciclo completo. É o que se pode pensar sobre a passagem da ferrovia sobre Campo Grande. Poderia argumentar-se que um equipamento com tal envergadura tecnológica e complexidade territorial somente entraria em falência se todo o sistema entrasse em colapso (PECQUEUR, 2009). Efetivamente o setor ferroviário brasileiro está em crise crônica há muito tempo e essa tese poderia explicar a longa e dolorosa agonia por que passou a Estrada de Ferro Noroeste do Brasil. Contudo, não esclareceria o completo descolamento de sua espacialização simbólica/arquitetônica/social/abstrata do espaço social campo-grandense. O ciclo das práticas espaciais envolvendo a passagem da ferrovia pela cidade de Campo Grande se deu paralelamente às transformações produtivas ocorridas no país e especialmente no Mato Grosso do Sul, determinando as construções simbólicas e territoriais vividas através do espaço por seus habitantes, levando a emergência de um espaço abstrato, erigido a partir da busca da modernidade e do progresso que viria com o trem. Esse espaço foi então dessemantizado, originando o não-espaço, o espaço do esquecimento, e a cidade não se revoltou, nem entrou em luto. Simplesmente começou a providenciar usos e novos significados em substituição àqueles que desapareceram, ressemantizando seu espaço, conforme sugere Teixeira Coelho (1999). 
Uma possível explicação sobre a espacialidade/territorialidade perdida está na natureza dos dois complexos que conviveram no mesmo território institucional. O complexo urbano é apropriado de várias maneiras pelos seus moradores (um tipo de territorialidade vital para as cidades), mas o complexo ferroviário é altamente especializado e seu uso limita-se ao fim ao qual foi construído. Assim, uma rua pode ter vários valores de uso e tipos de utilização, mas uma linha ferroviária só pode ser usada pelo trem e nunca vai se incorporar à dinâmica urbana sem ele, tornando-se uma prótese, um objeto estranho com o qual a cidade e seus habitantes têm que conviver. O mito da máquina do progresso é dissipado pelos transtornos que traz a rotina coletiva urbana, especialmente se deste mito restar apenas vestígios transformados em obstáculos.

Conclui-se, portanto, que se o modal ferroviário evaporou na cidade e seus vestígios estão sendo meticulosamente apagados foi porque talvez esse nunca tenha resultado em uma construção social, nem compôs, efetivamente, um território vivido. O espaço abstrato campo-grandense anuncia uma ainda difusa não-espacialidade que talvez esteja buscando se reconstruir. A reflexão sobre as dinâmicas da prática espacial erigida a partir da passagem do trem pelo espaço urbano da cidade de Campo Grande - um projeto de expansão e ocupação territorial -, a consolidação e o declínio de diversos ciclos produtivos 
em uma região, a preparação para a implantação da ferrovia, a convivência com o trem e seu posterior abandono - reflexo das mudanças dos paradigmas de desenvolvimento e das dinâmicas produtivas - , o processo de transformação desses espaços remanescentes em novas formas de uso e de significações. Todo esse aglomerado tem o potencial de possibilitar aos seus habitantes conceber um projeto de futuro comum para a vida a ser 'vivida' no espaço legado à cidade pela ferrovia.

\section{Referências}

ÁLBUM Gráfico de Mato Grosso (EEUU do Brasil). Corumbá; Hamburgo: Ayala \& Simon, 1914.

ARRUDA, Gilmar. A ferrovia Noroeste do Brasil: o ultimo trem para o sertão. Caderno de Estudos Urbanos. Campo Grande: Planurb, 1995.

DORATIOTO, Francisco. Maldita guerra. São Paulo: Cia. das Letras, 2002

CUNHA, Marcos André da Silva. Cluster étnico na área central de Campo Grande/MS: o comércio árabe da Avenida Calógeras. Dissertação de Mestrado. Campo Grande: UCDB, 2017. 
GRESSLER, Lori, Alice. Aspectos históricos do povoamento e da colonização do Estado de Mato Grosso do Sul: destaque especial ao município de Dourados. Estado: L. A. Gressler, 1988.

HERTZEMBERGUER, Herman. Lições de Arquitetura. 1a. ed. (Tradução Carlos Eduardo Lima Machado) São Paulo: Martins Fontes, 1996.

HOBSBAWN, Eric. A era das revoluções. 1789-1848. Rio de Janiero: Paz e Terra, 1986.

LEITAO, Lucia; LACERDA, Norma. O espaço na geografia e o espaço da arquitetura: reflexões epistemológicas. Cad. Metrop. São Paulo, v. 18, n. 37, p. 803-822, dez. 2016. Disponível em: http://www.scielo.br/scielo.php?script=sci_ arttext\&pid=S2236=99962016000300803-\&lng=pt\&nrmiso. Acesso em: 05 jun. 2018.

LEFEBVRE, Henri. The production of space. (Tradução de Donald Nicholson-Smith). Londres: Blackwell, 1991.

LORENZETTO, Mário Sérgio. Cabeza de Vaca e os mitos de seu tempo. São Paulo: FiuzaEditora, 2006

GULLAR, Ferreira. Trenzinho do Caipira. Folha de São Paulo, São Paulo, 06 de dezembro de 2009. Disponível em: https://www1.folha.uol.com.br/fsp/ilustrad/ fq0612200923.htm. Acesso em: 29 jul. 2018. 
MARQUES, Helder Gustavo. Memória e transformação urbana: uma análise do patrimônio ferroviário em Campo Grande - MS. Dissertação. São Paulo: Universidade de São Paulo, 2014.

Maciulevicius, Paula. Feita em meia hora, numa cabine, a música símbolo de MS: Trem do Pantanal. Campo Grande News, Campo grande, 11 de outubro de 2012. Disponível em: https://www.campograndenews.com.br/ lado-b/artes-23-08-2011-08/feita-em-meia-hora-numa-cabine-a-musica-simbolo-de-ms-trem-do-pantanal. Acesso em: 29 jul. 2018.

PECQUEUR, Bernard. A guinada territorial da economia global. Revista de Sociologia Política v.8 n.14, 2009.

POLIÃO, Marcus Vitrúvio. Da Arquitetura. (Tradução e notas Marco Antônio Lagonegro). São Paulo: Hucitec; Fundação para a Pesquisa Ambiental, 1999.

QUEIROZ, Paulo Roberto Cimó. Uma ferrovia entre dois mundos: a ferrovia EF Noroeste do Brasil na primeira metade do século 20. Campo Grande: Edufms, 2004.

REZENDE, Elaine Cristina Paganotti e CASTILHO, Maria Augusta de. Hotel Gaspar: identidade e memória no contexto do desenvolvimento local. Campo Grande: Life Editora, 2018. 
RIBEIRO, António Souza. Cartografias do não-espaço: viagens ao fim do mundo na literatura do holocausto. Revista Crítica de Ciências Sociais, 83. Coimbra, 2008.

TEIXEIRA COELHO, J. A construção do sentido na arquitetura. 4a. ed. São Paulo: Perspectiva, 1999.

TRUBILIANO, Carlos Alexandre Barros. Do “povoado de uma rua só" para "canaã do oeste": as políticas de normatização e controle social em campo grande (19051930). Artigo, Revista Urbana. São Paulo: Unicamp, 2012.

ZEVI, Bruno. Saber ver a arquitetura. 4a. ed. (Tradução Maria Isabel Gaspard, Gaetan Martins de Oliveira) São Paulo: Martins Fontes, 1994. 